\title{
Current efficiency of synthesis magnesium hydroxide nanoparticles via
}

\section{electrodeposition}

\author{
XinZhong. Deng ${ }^{1}$; YaoWu. Wang ${ }^{* 1}$; JianPing. Peng ${ }^{1}$; YueZhong. $\mathrm{Di}^{1}$
}

1: School of Materials and Metallurgy, Northeastern University, Shenyang, Liaoning 110819, China

${ }^{*}$ Corresponding author: E-mail: wangyw113@163.com; Tel: +86-24-83680508

Key words: magnesium hydroxide; nanoparticles; electrodeposition; current efficiency

Abstract:The nanograde particles of magnesium hydroxide $\left[\mathrm{Mg}(\mathrm{OH})_{2}\right]$ with lamella morphology were synthesized by the method of electrodeposition. The effects of operation parameters, such as $\mathrm{Mg}^{2+}$ concentration and electric current density, interpolar distance and $\mathrm{Na}^{+}$concentration on current efficiency of synthesis magnesium hydroxide nanoparticles were investigated. The results show that the current efficiency can be reach to $76.53 \%$ under the conditions of $\mathrm{Mg}^{2+}$ concentration $0.5 \mathrm{~mol} / \mathrm{L}, \mathrm{Na}^{+}$concentration $1 \%$, electric current density $40 \mathrm{~mA} / \mathrm{cm}^{2}$ and electrode interpolar distance $4 \mathrm{~cm}$. The samples were characterized by X-ray diffractions (XRD) and field emission scanning electron microscopy (FESEM).

\section{Introduction}

In recent years, the synthesis of nanoscale $\mathrm{Mg}(\mathrm{OH})_{2}$ has been the focus of considerable interest because of its potential properties in electronic, mechanical, electrochemistry, optical and topological ${ }^{[1-5]}$. Several methods have been used to prepare $\mathrm{Mg}(\mathrm{OH})_{2}$ with controlled shape and size, such as ultrasonic-assisted ${ }^{[6]}$, precipitation $^{[7]}$, sol-gel technique ${ }^{[8]}$, using bubbling setup ${ }^{[9]}$, hydrothermal route ${ }^{[10]}$ and electrolysis of an aqueous magnesium salt solution ${ }^{[11]}$,etc. Ranjit and Klabunde $^{[12]}$ have synthesized mesostructured $\mathrm{Mg}(\mathrm{OH})_{2}$ using different anionic surfactants as template, but their process limited due to low current efficiency and economically unacceptable. In present study, the $\mathrm{Mg}(\mathrm{OH})_{2}$ deposition processes from magnesium chloride hexahydrate was researched, and the effects of the variation of $\mathrm{Mg}^{2+}$ concentration, electric current density, interpolar distance and $\mathrm{Na}^{+}$concentration on current efficiency were studied.

\section{Experimental}

\section{Materials}

Magnesium chloride hexahydrate $\left(\mathrm{MgCl}_{2} \cdot 6 \mathrm{H}_{2} \mathrm{O}\right)$, sodium chloride $(\mathrm{NaCl})$, potassium chloride $(\mathrm{KCl})$ were supplied from Shenyang Chemical Reagent Co. Ltd, China, all of these chemicals are analytical pure grade and without further purification. Deionized water was employed for all experiments.

\section{Procedures of synthesis of $\mathrm{Mg}(\mathrm{OH})_{2}$ nanoparticles}

The electrolysis procedure were performed in a single conventional compartment cell(capacity is $2.5 \mathrm{~L}$ ). The anode is graphite plate and the cathode is stainless steel plates with smooth surface. The electrolysis experiments were took out at room temperature. In a typical run, $100 \mathrm{~g}$ of $\mathrm{MgCl}_{2} \cdot 6 \mathrm{H}_{2} \mathrm{O}$ is dissolve in $2 \mathrm{~L}$ of deionized water to make a mother solution, the electrodes surface is both $100 \mathrm{~cm}^{2}$ and the electrode interpolar distance is $4 \mathrm{~cm}$, the electric current density is 40 $\mathrm{mA} / \mathrm{cm}^{2}$ and the electrolysis time is $4 \mathrm{~h}$. When electrolysis reach a given time, nano- $\mathrm{Mg}(\mathrm{OH})_{2}$ can be 
obtained after the precipitates are filtered, washed with deionized water three times and dried in a vacuum drying oven at $70^{\circ} \mathrm{C}$ for $12 \mathrm{~h}$.

\section{Current efficiency}

The current efficiency is calculated by the following formula:

$$
\eta=\mathrm{m} / \mathrm{m}^{*}
$$

where $\eta$ is current efficiency, $m$ is the actual mass of metal hydroxide deposited, $m *$ is theoretical mass of metal hydroxide deposited. The actual mass of metal hydroxide deposited( $\mathrm{m})$ is determined by the mass after dry. The theoretical mass of metal hydroxide $\left(\mathrm{m}^{*}\right)$ is calculated by the Faraday's law:

$$
\mathrm{m}^{*}=\mathrm{ItM} /(\mathrm{nF})
$$

where $\mathrm{I}$ is the applied current, $\mathrm{t}$ is the time, $\mathrm{n}$ is the number of electrons transferred in the elementary act of the electrode reaction, $\mathrm{M}$ is the mole mass of the metal hydroxide and $\mathrm{F}$ is the faraday constant.

\section{Physical characterization of $\operatorname{Mg}(\mathrm{OH})_{2}$}

The X-ray diffraction (XRD) scans were recorded at room temperature on a Philips $X^{\prime}$ Pert PRO SUPER apparatus (Nicolet Instrument Co., USA) using $\mathrm{CuK}_{\alpha}$ radiation with $\beta$-Ni filter $(\lambda=$ $0.15406 \mathrm{~nm}, 40 \mathrm{kV}, 80 \mathrm{~mA}$ ) at a scan rate of $5 \%$ min (20). The morphology and size of the particles were characterized by a Zeiss field emission scanning electron microscopy (ULTRA PLUS at $25 \mathrm{kV}$ for SEM imaging, the sample was sputtered with Au before the test).

\section{Results and discussion}

Compared to the current method of producing $\operatorname{Mg}(\mathrm{OH})_{2}$, the method by a one-step cathodic electrodeposition process using magnesium chloride hexahydrate as raw material is simple and the pureness is high.

\section{Effect of $\mathrm{Mg}^{2+}$ concentration on current efficiency}

$\mathrm{Mg}^{2+}$ concentration in aqueous solution is one of the main factors affecting current efficiency of $\mathrm{Mg}(\mathrm{OH})_{2}$ electrodeposition. When $\mathrm{Mg}^{2+}$ concentration is low, the $\mathrm{OH}^{-}$which generated from cathode can not combine with $\mathrm{Mg}^{2+}$ quickly, affect the current efficiency. With the increase of $\mathrm{Mg}^{2+}$ concentration, the nanocrystals agglomeration became more serious ${ }^{[13]}$, affect the current efficiency further growth. The current efficiency was measured at various $\mathrm{Mg}^{2+}$ concentration and the other parameters is the same to typical run.

As shown in Fig. 1, it was found that when $\mathrm{Mg}^{2+}$ concentration is low, the current efficiency is about $50 \%$, with the $\mathrm{Mg}^{2+}$ concentration increase the current efficiency increases rapidly from $50 \%$ to $73 \%$. The current efficiency is stabilization when $\mathrm{Mg}^{2+}$ concentration is above $0.5 \mathrm{~mol} / \mathrm{L}$. The fact reveals that $0.5 \mathrm{~mol} / \mathrm{L} \mathrm{Mg}^{2+}$ concentration is optimal.

\section{Effect of electric current density on current efficiency}

Electric current density is another of the main factors affecting current efficiency of $\mathrm{Mg}(\mathrm{OH})_{2}$ electrodeposition. When electric current density is low, the formation rate of $\operatorname{Mg}(\mathrm{OH})_{2}$ is low too, it will affect $\mathrm{Mg}(\mathrm{OH})_{2}$ fall off from cathode, bring low current efficiency. While exaggerated elevate electric current density, will lead to electrodes calorific value increase, then the temperature of the electrolytic solution rises that will increase the solvent evaporation and change the electrolyte composition. It also increase energy consumption by elevate electric current density, affect its economy. The current efficiency of the $\mathrm{Mg}(\mathrm{OH})_{2}$ electrodeposition reactions were measured at various electric current density and the other parameters is the same to typical run.

As shown in Fig. 2, with the increase of current density, the current efficiency is increased then basically remain unchanged. When the electric current density is $10 \mathrm{~mA} / \mathrm{cm}^{2}$, the current efficiency 
is $46 \%$, and it quickly increases to $64 \%$ as the electric current density increases to $40 \mathrm{~mA} / \mathrm{cm}^{2}$. Above $40 \mathrm{~mA} / \mathrm{cm}^{2}$, the current efficiency is stabilization. The fact reveals that $40 \mathrm{~mA} / \mathrm{cm}^{2}$ electric current density is optimal.

\section{Effect of interpolar distance on current efficiency}

In the process of electrolysis, some of chlorine, produced by the cathode, conduct hydrolysis reaction and then formation $\mathrm{Cl}^{-}$. It will dissolve the precipitated magnesium hydroxide again when the interpolar distance is too small, affect the current efficiency. When plus the distance, the electrical resistance between electrodes is increases, so in order to maintain the electric current density need improve electric tension, which will increases more energy consumption. The current efficiency of the $\mathrm{Mg}(\mathrm{OH})_{2}$ electrodeposition reactions were measured at various interpolar distance and the other parameters is the same to typical run.

As shown in Fig. 3 the current efficiency increases with the increases of interpolar distance. When the interpolar distance is $2 \mathrm{~cm}$, the current efficiency is $44 \%$, and it increase to $65 \%$ when the interpolar distance became to $4 \mathrm{~cm}$. but it is stabilization when the interpolar distance is over $4 \mathrm{~cm}$. The result reveals that $4 \mathrm{~cm}$ interpolar distance is optimal.

\section{Effect of $\mathrm{Na}^{+}$concentration on current efficiency}

In the process of electrolysis, sodium chloride is added to the electrolytic solution can greatly reduce the solution resistance, namely, under the condition of not changing the interpolar distance can reduce the voltage between the electrodes, save power. The current efficiency of the $\operatorname{Mg}(\mathrm{OH})_{2}$ electrodeposition reactions were measured at various $\mathrm{Na}+$ concentrations(mass concentration) and the other parameters is the same to typical run.

As shown in Fig. 4, the current efficiency is increases firstly and then decreases with the increase of $\mathrm{Na}^{+}$concentration. Adding appropriate amount of $\mathrm{NaCl}$ is beneficial to improve the $\mathrm{Mg}(\mathrm{OH})_{2}$ electrodeposition reactions and increase current efficiency. But excessive $\mathrm{Na}^{+}$ concentration will hinder $\mathrm{Mg}^{2+}$ combine with $\mathrm{OH}^{-}$, and decrease current efficiency. The fact reveals that $\mathrm{Na}^{+}$concentration $1 \%$ is optimal. It was found that raising $\mathrm{K}^{+}$concentration had the same influence on current efficiency as increasing $\mathrm{Na}^{+}$concentration as discussed above.

In order to verification the result, a replication experiment was proceed. The experiment condition is $\mathrm{Mg}^{2+}$ concentration $0.5 \mathrm{~mol} / \mathrm{L}, \mathrm{Na}^{+}$concentration $1 \%$, electrodes surface $100 \mathrm{~cm}^{2}$, electrode interpolar distance $4 \mathrm{~cm}$ and the electric current density $40 \mathrm{~mA} / \mathrm{cm}^{2}$. Under this condition, the current efficiency can be reach to $76.53 \%$.

\section{Structure and morphology of $\mathrm{Mg}(\mathrm{OH})_{2}$ nanoparticle}

Fig. 5 shows the XRD pattern of the nano- $\mathrm{Mg}(\mathrm{OH})_{2}$ product. All diffraction peaks can be indexed very well as hexagonal phase $\mathrm{Mg}(\mathrm{OH})_{2}$ with calculated lattice constants of $\mathrm{a}=0.315 \mathrm{~nm}$ and $\mathrm{c}=0.477 \mathrm{~nm}$, which is agrees with the standard data (JCPDS 7-239). The size of $\mathrm{Mg}(\mathrm{OH})_{2}$ particles is calculated by the Debye-Scherrer formula ${ }^{[14]}$, based on the full width at half-maximum. The calculated crystal sizes is $23.7 \mathrm{~nm}, 15.6 \mathrm{~nm}$ and $21.7 \mathrm{~nm}$ correspond to (001), (101) and (102) diffraction peaks, respectively, which shows that as-synthesized $\mathrm{Mg}(\mathrm{OH})_{2}$ nanoparticles have nanometer level crystal size. In addition, the product prepared with this process has a high purity(the content of magnesium oxide is more than $99.6 \%$, which is measure by X-Ray fluorimetry)

The morphology of the nano- $\mathrm{Mg}(\mathrm{OH})_{2}$ sample was examined with FESEM. As shown in Fig. 6, the as-synthesized nano- $\mathrm{Mg}(\mathrm{OH})_{2}$ possess a lamella structure and the particle size distribution ranges from $40 \mathrm{~nm}$ to $200 \mathrm{~nm}$. Some nanoparticles are perpendicular to the picture, which clearly shows the thickness of these $\mathrm{Mg}(\mathrm{OH})_{2}$ nanolamellas below $20 \mathrm{~nm}$. 


\section{Conclusions}

Magnesium hydroxide with lamella morphology and high-purity could be synthesized by the method of electrodeposition. The current efficiency of $\mathrm{Mg}(\mathrm{OH})_{2}$ deposition can be over $76 \%$ under the condition of $\mathrm{Mg}^{2+}$ concentration $0.5 \mathrm{~mol} / \mathrm{L}, \mathrm{Na}^{+}$concentration $1 \%$, electric current density $40 \mathrm{~mA} / \mathrm{cm}^{2}$ and electrode interpolar distance is $4 \mathrm{~cm}$.

\section{Acknowledgements}

This work was financially supported by the National Natural Science Foundation of China (51404054).

\section{References}

1. S. Park and S.W. Chung, J. Am. Chem. Soc., 126 (2004), 1772-1773.

2. E.R. Leite and F.L. Souza, Chem. Mater., 17(2005), 4561-4563.

3. S.L. Chen and P. Dong, Chem. Mater., 17(2005), 5880-5883.

4. M.H. Bartl and S.W. Boettcher, J. Am. Chem. Soc.,126(2004), 10826-10827.

5. G.L. Zou and R. Liu, Mater. Lett., 61(2007),1990-1993.

6. G. W. Beall and E.S. Duraia, Powder. Technol.,19(2013),29-35.

7. P.R. Hornsby, Int. Mater. Rev.,46(2001),199-210.

8. G.H.A. Therese and P.V. Kamath, Chem. Mater.,12(2000),1195-1204.

9. X Li and Y.Y. Liu, Powder. Technol.,3(2014),51-58.

10. S. Ulutan and M. Gilbert, J. Mater. Sci.,35(2000),2115-2120.

11. Y. Tan and S. Srinivasan, J. Am.Chem.Soc., 127(2005),3596-3604.

12. K.T. Ranjit and K.J. Klabunde, Langmuir, 21(2005), 12386.

13. P. Wang and C. Li, Ceram. Int.,15(2011),138-145.

14. H.P. Klug and L.E. Alexander, X-ray Diffraction Procedures, 1962 , New York, Wiley. 


\section{Figure Captions}

Fig. 1. Relationship between $\mathrm{Mg}^{2+}$ concentration and current efficiency for $\mathrm{Mg}(\mathrm{OH})_{2}$ deposits

Fig. 2. Relationship between electric current density and current efficiency for $\mathrm{Mg}(\mathrm{OH})_{2}$ deposits

Fig. 3. Relationship between interpolar distance and current efficiency for $\mathrm{Mg}(\mathrm{OH})_{2}$ deposits

Fig. 4. Relationship between $\mathrm{Na}^{+}$concentration and current efficiency for $\mathrm{Mg}(\mathrm{OH})_{2}$ deposits

Fig. 5. X-ray diffraction (XRD) pattern of $\mathrm{Mg}(\mathrm{OH})_{2}$ nanolamella.

Fig. 6. Scanning electron microscopy (SEM) image of $\mathrm{Mg}(\mathrm{OH})_{2}$ nanolamella.

Fig. 1.

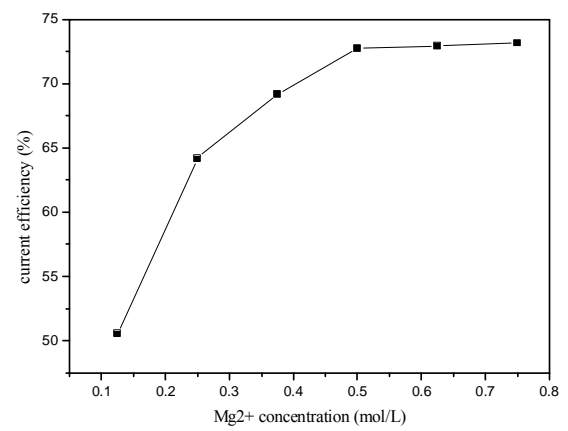

Fig. 3.

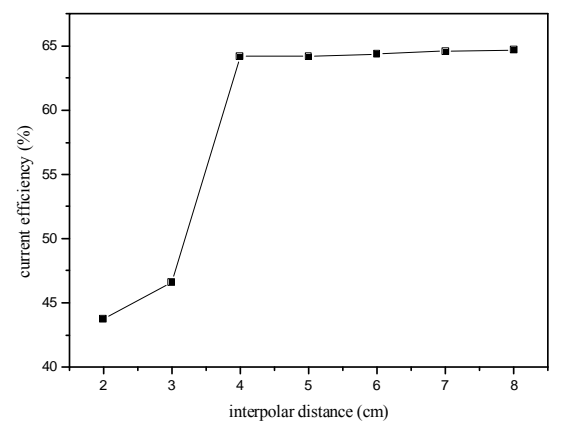

Fig. 5.

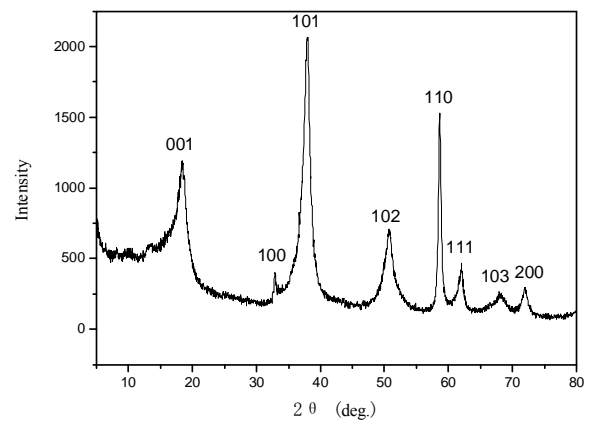

Fig. 2.

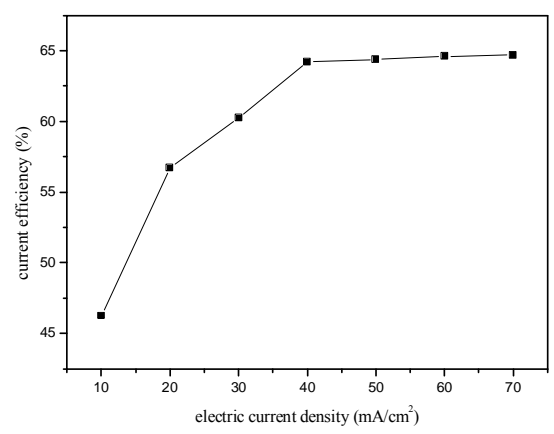

Fig. 4.

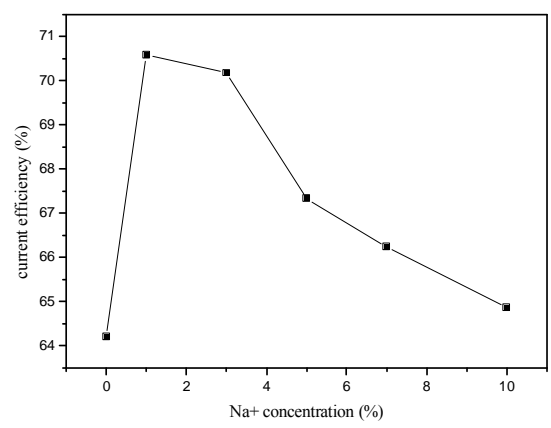

Fig. 6 .

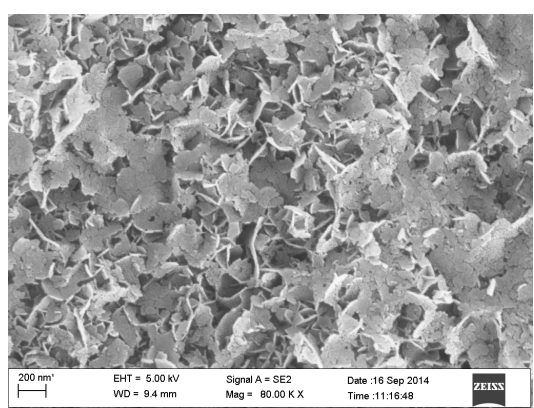

